\title{
Teacher Mediation in a Collaborative Learning Laboratory of Physics, a Virtual Environment for Teaching and Learning
}

\author{
Dante Alighieri Alves de Mello, ${ }^{1,2}$, Shirley Takeco Gobara ${ }^{3}$ \\ ${ }^{1}$ Technological Axis of Information and Communication, Federal Institute of Mato Grosso do Sul, Aquidauana, \\ Brazil \\ ${ }^{2}$ Graduate Program in Education, Federal University of Mato Grosso do Sul, Campo Grande, Brazil \\ ${ }^{3}$ Institute of Physics, Federal University of Mato Grosso do Sul, Campo Grande, Brazil \\ Email: dante.mello3@gmail.com, stgobara@gmail.com
}

Received 17 August 2014; revised 13 September 2014; accepted 6 October 2014

Copyright $(02014$ by authors and Scientific Research Publishing Inc.

This work is licensed under the Creative Commons Attribution International License (CC BY).

http://creativecommons.org/licenses/by/4.0/

(c) (i)

\section{Abstract}

We know that physics is a difficult subject for many students to understand. From this observation, several studies have been performed to investigate the causes and possible solutions to this problem. Among the numerous existing lines of study, we find investigations on the use of Information and Communication Technologies (ICT). Based on Vygotsky's theory, we developed a Virtual Environment for Teaching and Learning (VETL) to foster interaction and collaborative participation among students, and between them and the teacher, to solve problems in physics. We seek to present in this paper how teacher mediations should be conducted in this environment in order to foster collaborative interactions and thus facilitate the internalization of scientific concepts by students. We found that students have an expectation as to the participation of the teacher in the environment, and as a consequence the teacher should seek to virtually interact with all groups, even those who have managed to solve the problem by themselves, at least to communicate to the students if they solved it correctly.

\section{Keywords}

Mediation, Virtual Environment for Teaching and Learning, Collaboration, Interaction, Zone of Proximal Development, Actual Development Level, Collaborative Learning Laboratory of Physics

\section{Introduction}

With the growing development of Information and Communication Technologies (ICT), in particular with the popularization of computers, smartphones and the Internet, the school environment is being challenged to inno- 
vate and to promote quality education mediated by the latest technological features, especially the Virtual Learning Environments (VLE) and the Virtual Environments for Teaching and Learning (VETL). The VETL denomination concerns broader environments than the VLE, as they integrate the actions of teaching that are fundamental to learning, i.e., they take into account the role of the teacher in organizing, planning, implementing and evaluating educational activities on the environment (Nardin, Fruet, \& Bastos, 2009). The VETL support distance education, be it fully or partially online, as they present characteristics such as connectivity and hypertext navigation interface, and also integrate, in a single environment, tools of hypermedia, activity and communication (which can be synchronous, such as chat rooms, and asynchronous, like forums), that favor and promote, in particular, the interaction among students and between them and the teacher.

Based on the potential of such an environment, we developed a VETL for teaching physics, called Collaborative Learning Laboratory of Physics (LAFIS, for its acronym in Portuguese), freely available at http://www.lafis.ufms.br (Mello \& Gobara, 2013b). We sought to ground our efforts on a theoretical framework of learning for the design and development of this environment as well as for the analysis of the classes held, to evaluate it as a supportive environment for collaborative learning. Basically, LAFIS presents two environments, identified as virtual laboratories. These laboratories were structured to promote collaborative interactions between the individuals involved in an educational system comprising the students, the teacher and the problems to be solved.

For the evaluation, we developed a survey aimed at identifying how this VETL could be used, as well as potential difficulties for students, through the analysis of the interactions between them, the computer and the teacher, based on Vygotsky's ${ }^{1}$ theory. To achieve this goal, we initially performed a step called "pilot phase" and subsequently evaluated the use of LAFIS during the development of some didactic sequences, through which we tried to learn the extent to which the argumentations that take place in the environment and the consistency of the sequence should be guided, so that the environment can foster the learning of concepts of physics.

The results we obtained during the pilot stage of our research were encouraging. This testing of LAFIS was held primarily to identify and correct errors in the presentation and programming of the environment (Mello \& Gobara, 2013a). In addition to these corrections, we found that the interaction between students would necessarily happen if the problem was proposed in such a way that its solution depended on the help of a colleague. Therefore, we restructured LAFIS so that certain elements fundamental to the solution were initially available to just one of the students, with the possibility of "teleporting" them to the other lab.

Still in the "pilot phase", we proposed to the students a problem that contained a link to a simulation of $\mathrm{PhET}^{\circledR}$ (2014) regarding periodic waves on a string. Students had to set up the simulation according to the parameters presented in the statement of the problem and could interact with each other to identify quantities such as wavelength, amplitude, period, frequency and speed of propagation of the wave (Mello \& Gobara, 2013b). We found that LAFIS favored the collaborative interaction among the students investigated, since $78 \%$ of the solutions posted in the chat originated from collaborative interactions among students or between them and the teacher. Furthermore, in the written evaluation applied after the VETL class, students solved problems they could previously only solve with the help of peers or the teacher, evidencing the potential of using this environment, in association with the developed instructional sequence and the teaching procedures, for learning and hence for the development of students.

In this article, in particular, we present theoretical and practical orientations for teachers who may come to use LAFIS in their pedagogical practice, so that they can take advantage of the environment's potential and also submit it for evaluation in other social contexts.

Initially, we present the theoretical framework of learning that served as a basis for the development of LAFIS and the analysis of the lessons mediated by it. We then seek to explain the dynamics of the environment, its tools and how to register problems in it. Afterwards we present some guidance as to the formation of students' groups to solve problems, taking into account their learning level. Finally, we suggest the teacher some ways to interact in the classroom, based on the experiences already carried out on this environment in the schools we investigated.

\section{Theoretical Framework for Learning and the Teaching Practice Mediated by VETL}

The development of LAFIS and the analysis of classes held on it were based on the ideas of Vygotsky (2007,

\footnotetext{
${ }^{1}$ With the exception of one of the references in this work, which uses the spelling "Vigotskii”, we will refer to the author using the spelling "Vygotsky".
} 
2008), a theorist of learning for whom students' collaboration, among themselves or between them and the teacher, is essential for the development of skills and strategies fundamental for the solution of problems. Vygotsky's theory assumes that learning is enhanced when it acts in the so-called Zone of Proximal Development (ZPD) of the learner. To explain the concept of ZPD, Vygotsky defined two levels of human development: the Actual Development Level (ADL), which corresponds to psychic functions already developed (skills and knowledge that have been internalized by the student) and is estimated by that which the person performs alone, without cooperation, thus being, at least theoretically, "measurable" by individual tests; and the Level of Potential Development (LPD), determined by problem solving under adult guidance or in collaboration with teammates who have already developed such skills.

The ZPD is an intermediate level of development, in which the student can solve certain problems only with the mediation of another person. Once the concepts associated with the resolution of these problems are internalized by the subject, he will be able to solve them irrespective of aid. In this case, there will be an increase in the Actual Development Level of the learner, which for Vygotsky demonstrates that learning can precede and leverage development.

Figure 1 shows a schematic representation of the levels of development and the ZPD.

As we can see, the movement described, starting from the student's ADL and working in their ZPD to eventually arrive at a new ADL, shows that for Vygostky the learning process is dynamic and dialectical. But how can teachers apply the fundamentals of Vygostky's cultural-historical theory in their teaching? Gasparin (2009) sought to answer this question by presenting a didactic proposal whose theoretic-methodological foundation is historical-dialectical materialism.

Basically, the teachers must perform their work starting from the social practice of the student, i.e., the identification of (spontaneous) concepts found in his ADL. Then they should work with theoretical abstraction, presenting to the student the scientific concepts they want to teach, always trying to work within the student's ZPD. Finally, they return to the new social practice of the individual, assessing whether or not the student internalized the concepts which were studied. If there was (even partial) learning, according to the assumptions of Vygotskian theory, it is considered that the learner's ADL was reconfigured. From this point on the teacher can work with new concepts, since Vigotskii (2010) states that, from the point of view of the students' overall development, it is ineffective to want to teach them what they already know, i.e., knowledge that is already in their ADL. However, if after class the teacher comes to the conclusion that there has been no learning yet, or that there was only partial learning, she should continue to work in the students' ADL, providing new mediations, encouraging new interactions and proposing new assessments to identify if the student can already do independently what he could previously do only with assistance (ZPD).

We tried to use LAFIS in the classroom based on these theoretical and methodological orientations, thus seeking to promote collaborative interactions among the students. Roschelle \& Teasley (1996) make a distinction between cooperation and collaboration. Cooperation is characterized by division of labor among the participants, i.e., it is an activity in which each person is responsible for part of the resolution of the problem in question. Collaboration involves the coordinated efforts of all group participants in order to solve the problem together. We designed LAFIS aiming to promote collaborative interactions in its environment. We know that this depends on how students interact with each other while solving the problem, but we believe that teacher mediation can direct the group's actions so that the work will be collaborative in nature.

\section{Structure and Operation of the Virtual Environment for Teaching and Learning}

LAFIS was designed to promote the virtual interaction of students with one another and with the teacher through the chat room available on the environment. The program consists of two environments, identified as virtual laboratories. The information exchanged between the students and between them and the teacher is stored in a database. The teacher may in turn register problems on the environment or use the problems previously registered in the questions database.

Figure 2 shows the screen of the "Questions Database", available in the teacher's restricted area. There the teacher can disable or enable a problem for the students to solve, exclude problems, edit them (as long as they have not been registered by another teacher), and form groups of students to solve them, or mediate the students' groups synchronously or asynchronously.

After choosing the problem to be solved by the class, the teacher should form groups of students, who will 


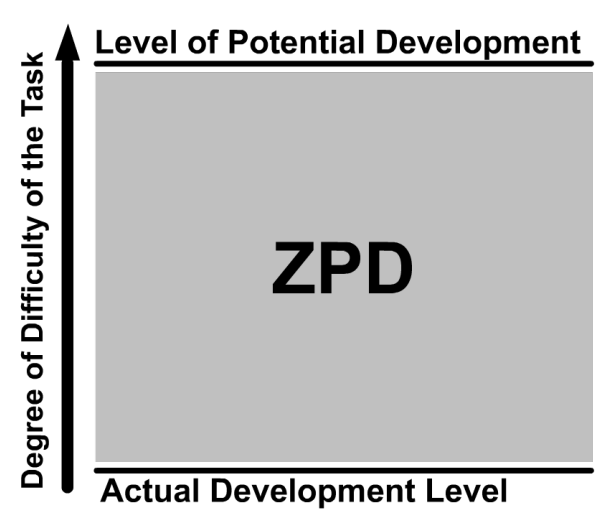

Figure 1. Schematic representation of the Zone of Proximal Development (Silva, 2009, p. 16).

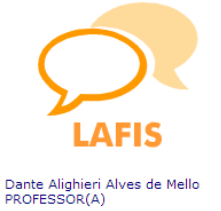

\section{Laborabório de Aprendizagern Colaboraliva de Fisica}
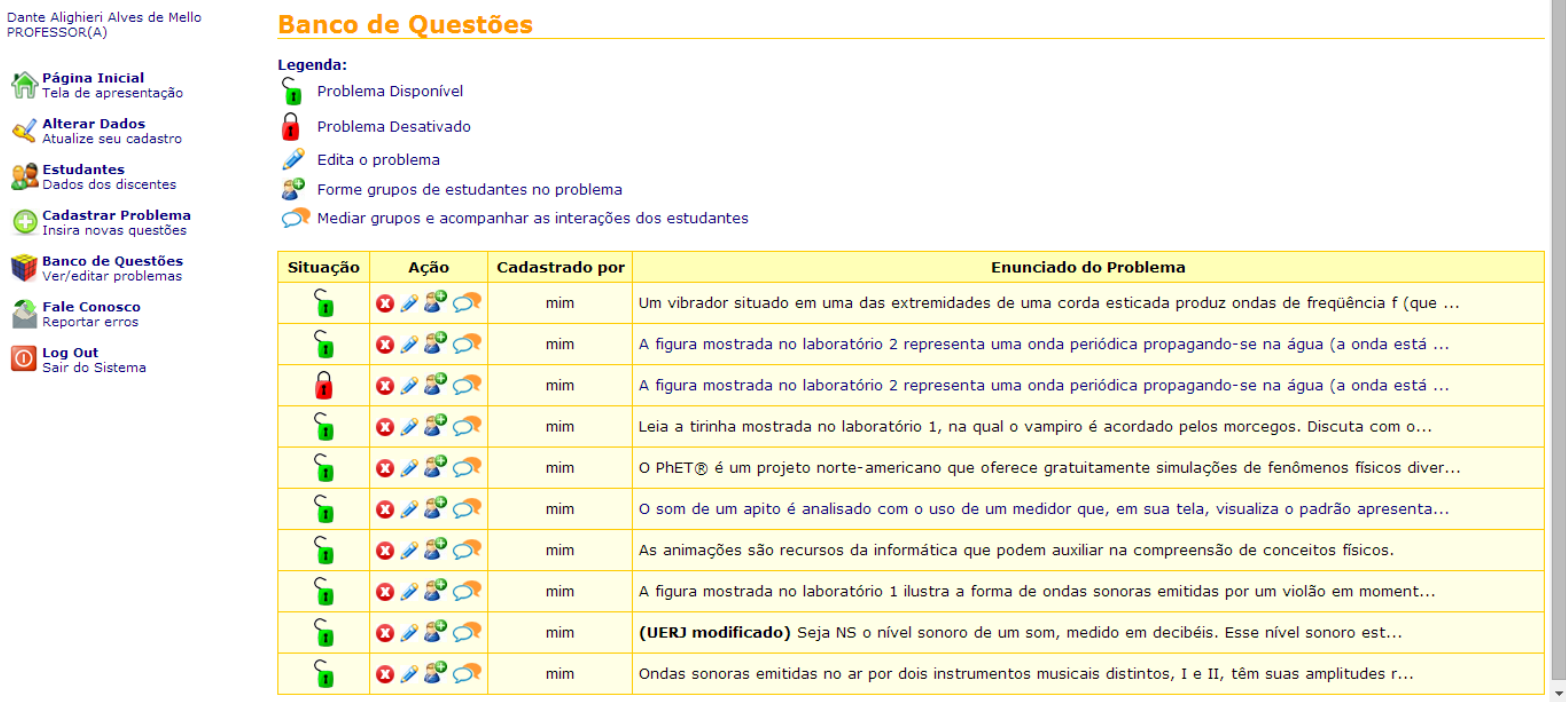

Figure 2. “Questions Database” screen, available to teachers in their restricted area.

have access to different information distributed in the two virtual laboratories. To do so, she just clicks on the group-forming icon of a given problem, as shown in Figure 2, selects the class for which the lesson will be held, and finally selects in the presented list which students will be assigned to each laboratory.

In general, we suggest that students are grouped in pairs, so that each of them can be assigned to one of the virtual laboratory environment. However, we know that it is possible for classes to have an odd number of students. In such cases, one of the groups may have three students, two of them assigned to laboratory 1 and the third one to laboratory 2.

To solve the proposed problem, the students must exchange the information distributed in each laboratory between them. Each student must have access to only one of the laboratories. Thus, through collaborative interactions, the group will be able to virtually solve the problem.

Since this is a proposal grounded in Vygotsky's theory, our thesis is that students' learning can be enhanced when there is an interdependent relationship in the interaction between the learners to solve certain problems registered in LAFIS. To promote this interdependence we designed the environment so that certain elements, such as figures, tables, graphs, or equations, are available for only one student at a time. Thus, when the student 
assigned to a given laboratory clicks on an element, she "beams" it to the other lab. In this way, students must necessarily interact with each other so that the problem can be solved. Figure 3 shows an example of such a problem, viewed by a student assigned to laboratory 1 .

Note in Figure 3 that the student in laboratory 1 initially, has access to the figure (graph) required to solve the problem. On the other hand, when the student in laboratory 2 opens her environment, she has access to a table, that is also needed to solve the problem, as shown in Figure 4. In this particular problem we chose to make the equation available for both students at the same time.

Note that the problem can only be solved if the students have access to both registered elements, i.e., the table and the graph. However, to induce interaction among students, the graph is initially only available in laboratory 1 , while the table can be found only in laboratory 2 . As we have previously stated, students may exchange these elements among themselves (by clicking on them) as often as deemed necessary to solve the problem. The

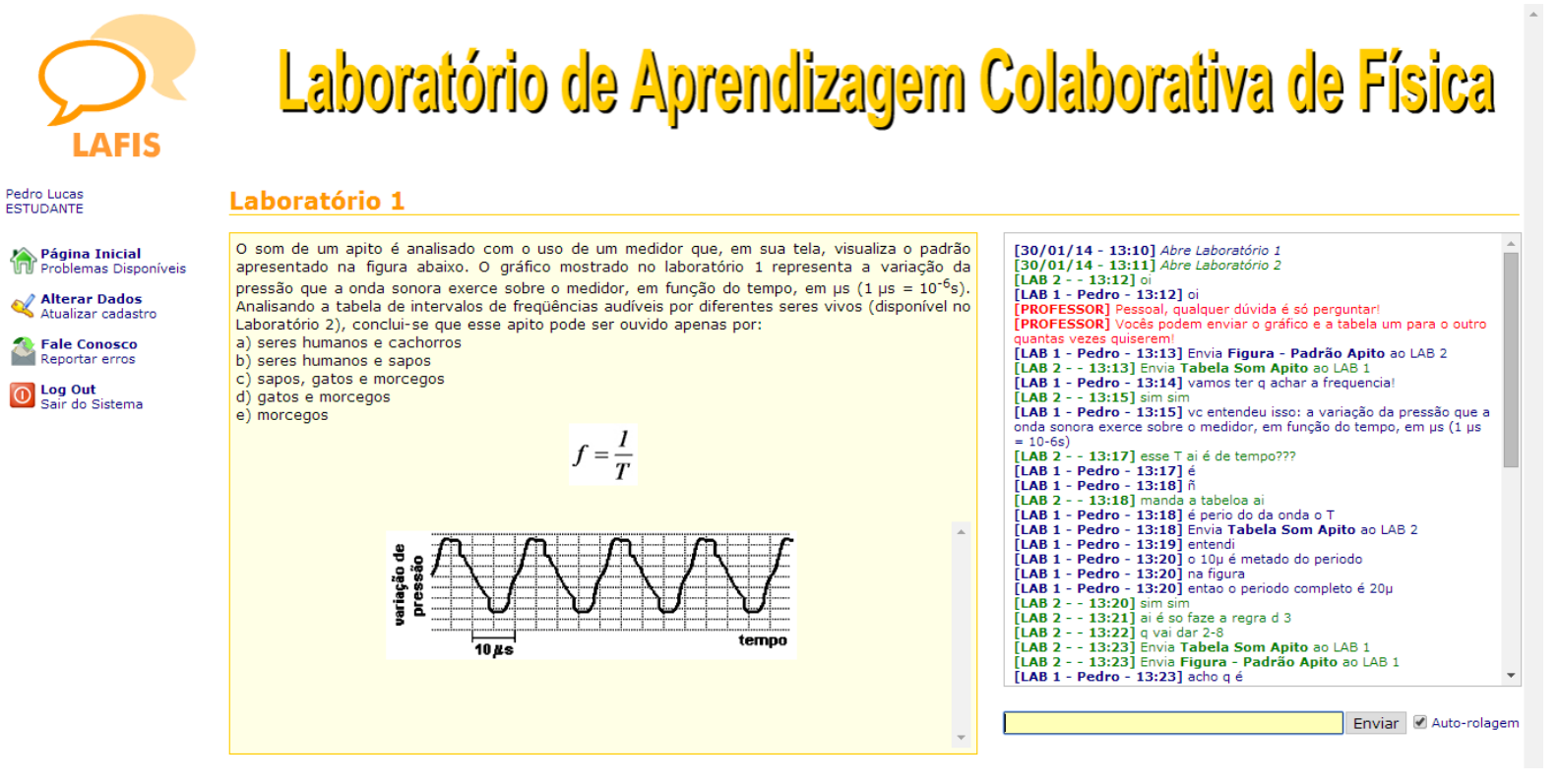

Figure 3. Screen presented to a student assigned to laboratory 1.
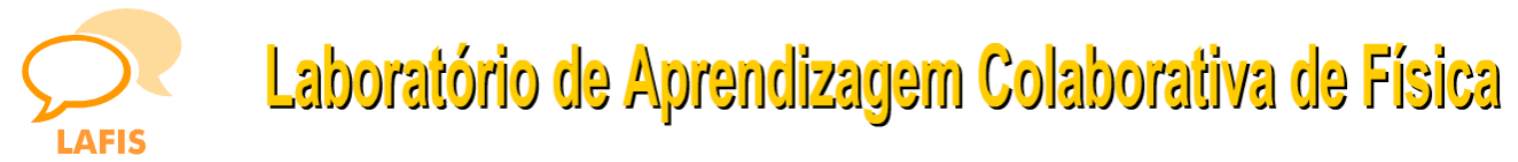

Marcos Paulo
ESTUDANTE

命 Página Inicial

$\checkmark$ Atturar Dados

Fale conosco
Reportar erros

Laboratório 2

(1) Log Out
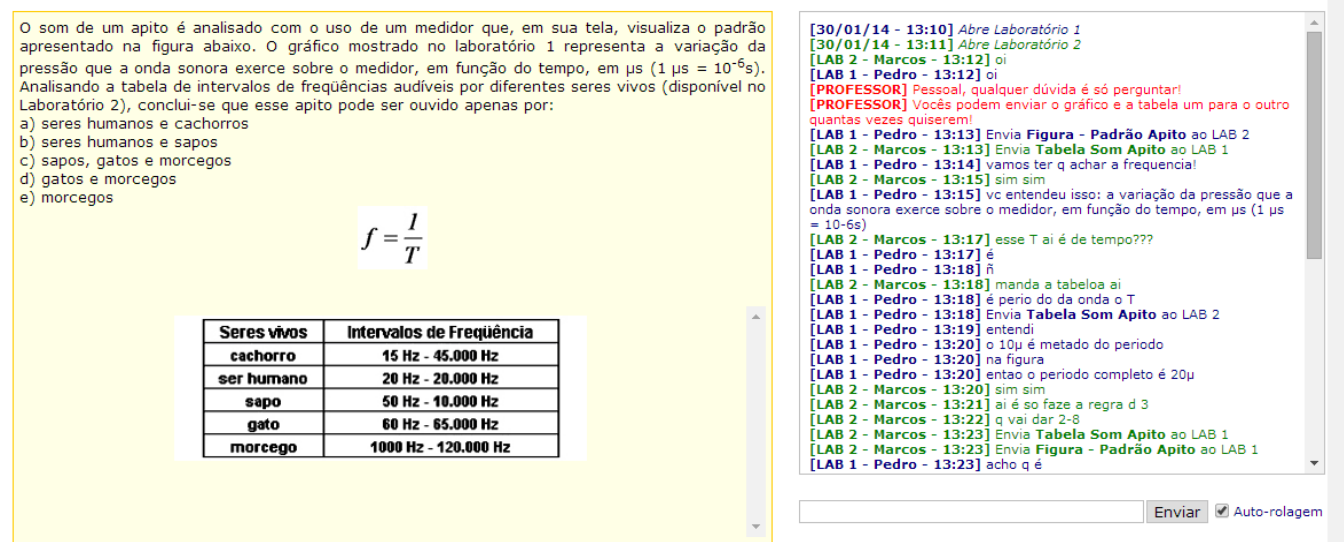

Figure 4. Screen presented to the student assigned to laboratory 2. 
fact is that, every time a student wishes to have access to an element of another laboratory, he must establish an interaction with his partner, in order to ask for the element in question.

To propose such problems in the environment, we had to take into account some pedagogical aspects, as presented below.

\section{Proposing Problems in LAFIS}

LAFIS was based on the VELT called LEDVI, for the acronym in Portuguese of Virtual Interactive Educational Laboratory (Silva \& Gobara, 2007). LEDVI also presents certain elements in only one of its laboratories, with the possibility of them being teleported to the other one, and also allows virtual interaction among students. LAFIS, in turn, provides the teacher with a functionality that was not yet present in LEDVI: the possibility of inserting problems in the environment.

Although the registration of a problem in LAFIS is a relatively simple process, the teacher should consider the following pedagogical aspects when proposing a problem in this environment:

1) Evaluate whether the physics concepts related to the problem can be found in the Actual Development Level (ADL) or in the Zone of Proximal Development (ZPD) of the students;

2) Make certain elements (tables, figures, graphs, equations) available on only one of the laboratories. Make sure the problem can only be solved by using these elements.

If the teacher deems necessary to make certain elements available in both laboratories, this can be done using the "Attach Files" tool. We did that for the equation of frequency as a function of period, as shown in Figure 3 and Figure 4.

With regard to the identification of the students' development level, the application of individual tests is a way to evaluate whether certain concepts are already in their Actual Development Level (Vygotsky, 2007). If the student can only solve the problems with assistance from a more experienced colleague, or even the teacher, the conclusion, according to the adopted framework, is that these concepts are in the student's Zone of Proximal Development.

Therefore, LAFIS can be used both to identify the students' development level and to provide new learning situations. We will now present some suggestions for forming student groups in this environment, based on the adopted theoretical framework and on the classes we have already held with LAFIS.

\section{Group Composition in LAFIS}

The teacher is free to form student groups that will solve the problems in the environment. Strictly speaking, according to Vygotsky's theory, the optimal groups are those formed by students with distinct development levels, so that a learner may help her colleague solve problems. However, one should make sure that the problem can actually be solved by the students, i.e., that the concepts to be internalized are part of their Level of Potential Development.

Thus, we suggest that in forming the groups the teacher should:

1) Avoid forming groups in which the concepts are already on the ADL of both students, because, as noted by Vygotsky, it is inefficient to try to teach what the student already knows.

2) Try to form groups considering that the concepts of the problem in question should be in the ADL of one of the students and in the ZPD of the other. In such cases it is possible that the problem will be solved by the students without the need of teacher mediation. Even so, we recommend that the teacher follows their interactions, and that she signals that she is doing so to the students whenever possible.

3) Form groups in which the concepts are in the ZPD of both students. In these cases teacher mediation may be essential to the full resolution of the problem.

As we can see, the individual application of a test before a class with LAFIS is essential to identify the students' spontaneous concepts and to verify if the necessary problem-solving concepts are already in their ADL.

Another key point is the application of an evaluation after the LAFIS class, since in this way the teacher can identify if the environment interactions were actually collaborative, i.e., if they really leveraged the learning processes arising from a coordinated effort by the students to solve the problem together. This evaluation can be made in the environment itself, through the application of another problem. However, we have sought to make it individually and out of the environment, because then we can more easily identify the individual progress of each student. In particular, we try to see if the student went on to solve certain problems independently, without 
further need of the assistance of others, which suggests that he has advanced to a new Actual Development Level.

We present below some suggestions about how teachers who want to use LAFIS in their classes should behave in the environment. Such practices are part of the results we obtained applying LAFIS in two public school classes in the city of Aquidauana-MS, Brazil.

\section{The Pedagogical Practice Mediated by LAFIS}

To mediate students we suggest that the teacher open a browser tab or window for each group to be mediated. This way all groups can be tracked simultaneously. In theory, there is no limit to the number of groups formed in the environment, depending on the amount of students that the teacher can mediate in the same class. In the classes we run, we mediate an average of about twenty students, disposed in ten groups of two students each.

Because these lessons are of an interactive nature, we observe that they tend to require more time for their execution. Therefore, when planning a lesson using LAFIS, the teacher should prepare it so that there will be enough time for discussing the students' answers, particularly when wrapping up the lesson, at which point the teacher can ask whether the answers make sense phisically. The most effective mediation is not one in which the teacher simply gives the problem's answer to the students, but one in which she returns them the question, giving them tips but affording them the act of reflection that leads to the expected answer. It is by analyzing the answers to her questions that the teacher can identify the students' intellectual progress.

In this sense, paying close attention to the students' answers is an important point to be observed in LAFIS. In certain groups, for example, we note that both members agreed on the same answer (which was incorrect), and in such cases teacher mediation was essential to differentiate between spontaneous concepts and scientific concepts.

Another orientation arising from our practice with LAFIS is the need for mediation in all groups, without distinction. Even if a particular group develops the activity as expected, i.e., correctly reaches the solutions, the teacher must also mediate it. We found in certain student groups that they miss the interactions with the teacher, even if only to confirm that the answers are correct, as shown by the interactions in Box 1.

For virtual interactions to be satisfactory, the teacher should try to stay alert to the possibility that the students are merely posting the answers correctly, instead of actually interacting and discussing the results. In this way he can promote more effective interactions within groups, especially those in which only one of the students might be posting the answers in the environment. The teacher should direct students to the proposed activity, since, as much as in traditional classrooms, virtual interactions are also prone to the so-called "side conversation".

Another interesting aspect of this environment is the ability to identify spontaneous concepts of the students. In several classes we found that many of them, even after studying with the teacher the scientific concept of wave amplitude, still had a fairly common concept that the amplitude would be the distance between the crest and the trough of the wave. For example, in a problem for which the expected wave amplitude was $20 \mathrm{~cm}$, several students posted the value $40 \mathrm{~cm}$. In such cases, we try to use the student's own spontaneous concept to present the corresponding scientific concept, as can be seen in Box 2.

Even with these teacher mediations, the evaluation after the lesson on LAFIS showed us that this particular student still had the spontaneous concept mentioned in Box 2. This reinforces what we already said earlier about the importance of conducting an evaluation after the LAFIS lesson. The evaluation may be the end of a cycle, in which a particular learning process was materialized, or simply the restarting of the process, surely including the adaptations the teacher deems necessary for the student to have a new opportunity to internalize the concepts that remained in her ZPD.

\section{Conclusion}

We see that LAFIS is a collaborative Virtual Environment for Teaching and Learning that can help teachers identify the Actual Development Level of their students and the qualitative changes in their Zone of Proximal Development.

Quantitative analyses of the data sources for this research suggest that, under certain conditions (already mentioned), LAFIS favors collaborative interaction among the students, because the interdependence between them in the environment can promote interactive processes that can be converted into collaborative action if the subjects assist each other to solve the problems posed. 


$$
\begin{aligned}
& {[L A B 2 \text { - Maria] teacher doesn't even ee us ‘- }} \\
& {[L A B 2 \text { - Maria] \# see }} \\
& {[L A B 1 \text { - João] LOL }} \\
& \text { [LAB 1-João] yeah... }
\end{aligned}
$$

Box 1. Dialog of a pair of students who hoped for more interaction with the teacher.

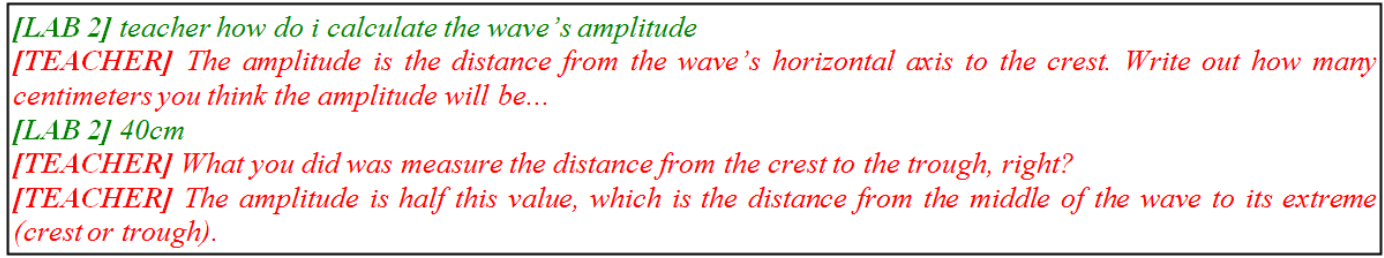

Box 2. Teacher mediation to help the student to graphically identify the amplitude of a wave.

Among the subjects investigated, we found cases of students who received aid from their peers and were thus able to solve the questions posed, as well as cases in which both of the group students did not understand or know how to solve the proposed problem, but were able to do it successfully after being helped by the teacher.

The environment has been tested with students from two public schools with very different sociocultural realities (Mello \& Gobara, 2014, 2013a, 2013b). The results showed the strong influence of these realities, as already predicted by the theoretical approach adopted.

We also notice that one of the main focuses that the teacher should have in her mediations through LAFIS is to make sure the interaction between students is actually happening among all group members. If a particular student is not participating in the resolution of the problem, which can happen when the group is composed of three members, so that one of them can have a more passive attitude, it is the attentive teacher's job to intervene and encourage her participation, either by asking questions or by requesting that she performs some procedure that promotes her learning, such as the presentation of the calculations made to obtain a certain value, or the explanation of the solution to the partner.

Asking students to describe the procedure used to obtain the answers was crucial to check whether the steps taken toward the solution were consistent, proving that the answer was not obtained by chance and thus clarifying if the basic concepts fundamental for the problem's solution were indeed internalized by the subjects and, consequently, increased their Actual Development Level (ADL).

\section{Acknowledgements}

D. A. A. MELLO thanks the "Coordenação de Aperfeiçoamento de Pessoal de Nível Superior (CAPES)" for the $\mathrm{PhD}$ scholarship granted for the development of this research.

\section{References}

Gasparin, J. L. (2009). Uma Didática para a Pedagogia Histórico-Crítica (5th ed.). Campinas, SP: Autores Associados.

Mello, D. A. A., \& Gobara, S. T. (2013a). LAFIS: Um Laboratório Virtual de Aprendizagem Colaborativa de Física. IX Encontro Nacional de Pesquisa em Educação em Ciências. SP: Águas de Lindóia. http://www.adaltech.com.br/sigeventos/abrapec2013/inscricao/resumos/0001/R0240-1.PDF

Mello, D. A. A., \& Gobara, S. T. (2013b). Analysis of Interactions in a Virtual Learning Environment Based in Vygotsky’s Theory. Creative Education, 4, 54-60. http://dx.doi.org/10.4236/ce.2013.410A009

Mello, D. A. A., \& Gobara, S. T. (2014). LAFIS, um Ambiente Virtual de Aprendizagem Colaborativa de Física Embasado na Teoria de Vygotsky. Revista Tecnologia Educacional, 205, 16-30. http://www.abt-br.org.br/images/rte/205.pdf

Nardin, A. C., Fruet, F. S. O., \& Bastos, F. P. (2009). Potencialidades tecnológicas e educacionais em ambiente virtual de ensino-aprendizagem livre. Novas Tecnologias na Educação, 7, 1-10.

PhET (2014). Interactive Simulations. http://phet.colorado.edu

Roschelle, J., \& Teasley, S. D. (1996). The Construction of Shared Knowledge in Collaborative Problem Solving. In C. E. O’Malley (Ed.), Computer Supported Collaborative Learning (pp. 69-97). Heidelberg: Springer-Verlag. 
Silva, A. F. (2009). RoboEduc: Uma metodologia de aprendizado com Robótica Educacional. Ph.D. Thesis, Natal: Universidade Federal do Rio Grande do Norte.

Silva, E. W. F. M., \& Gobara, S. T. (2007). LEDVI, Ambiente virtual interativo mediado a distância. Revista Novas Tecnologias na Educação, 5, 1-8.

Vigotskii, L. S. (2010). Aprendizagem e Desenvolvimento Intelectual na Idade Escolar. In L. S. Vigotskii, A. R. Luria, \& A. N. Leontiev (Eds.), Linguagem, Desenvolvimento e Aprendizagem (pp. 103-117). São Paulo: Ícone Editora.

Vygotsky, L. S. (2007). A formação social da mente (7th ed.). São Paulo: Martins Fontes.

Vygotsky, L. S. (2008). Pensamento e Linguagem (4th ed.). São Paulo: Martins Fontes. 
Scientific Research Publishing (SCIRP) is one of the largest Open Access journal publishers. It is currently publishing more than 200 open access, online, peer-reviewed journals covering a wide range of academic disciplines. SCIRP serves the worldwide academic communities and contributes to the progress and application of science with its publication.

Other selected journals from SCIRP are listed as below. Submit your manuscript to us via either submit@scirp.org or Online Submission Portal.
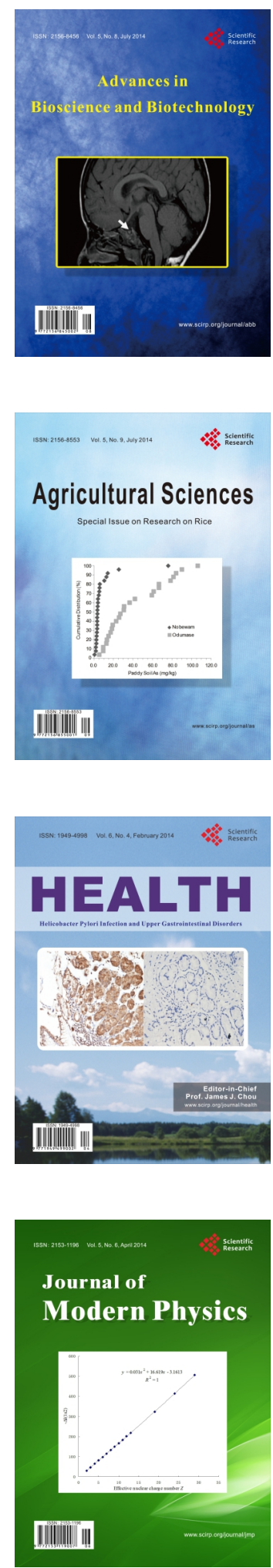
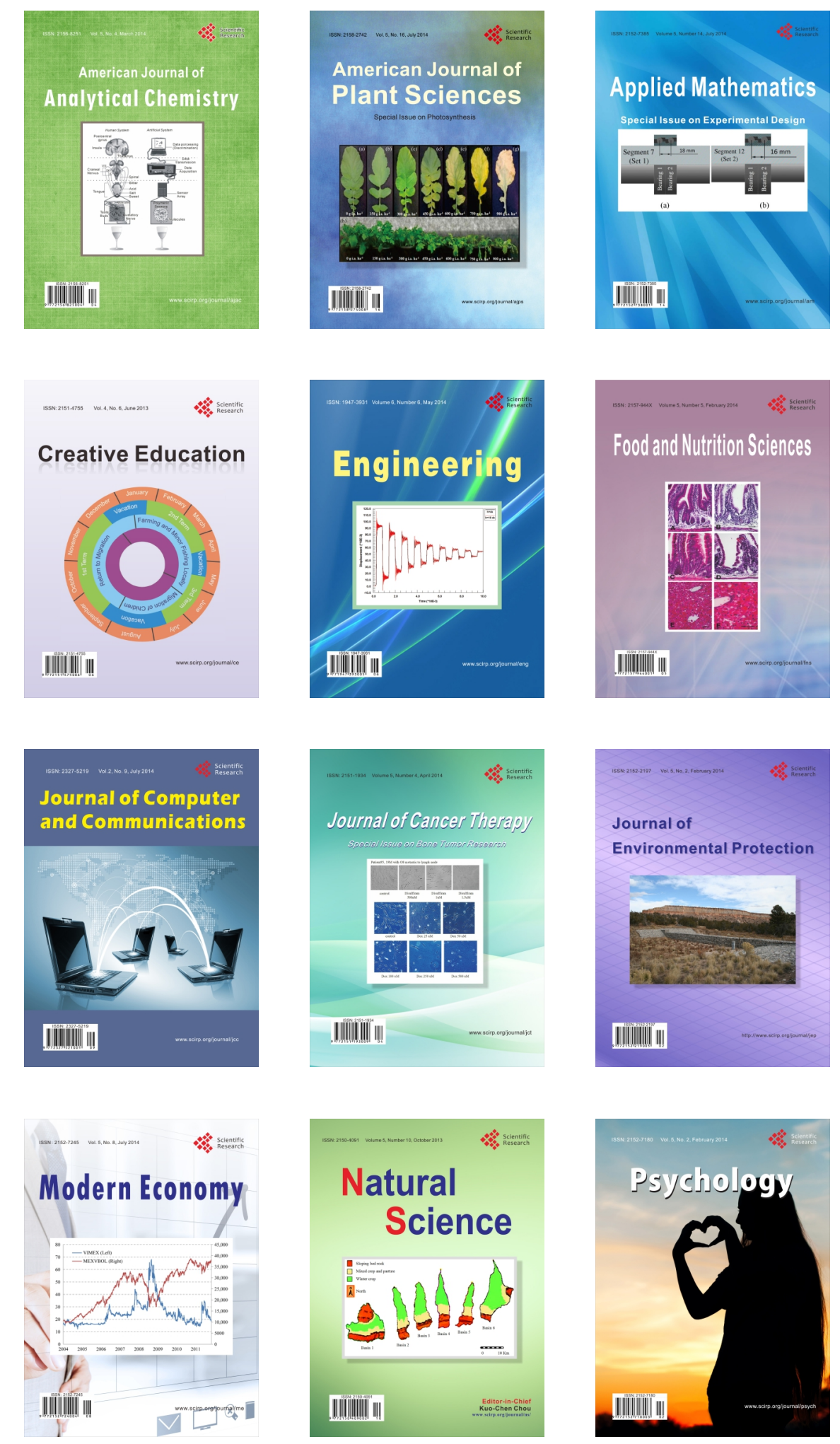